\title{
Macroscopic Profile Modification and Microscopic Displacement Mechanism of Weak Gel Flowing in Porous Media
}

\author{
Jian Wang, ${ }^{1}$ Bo Kang, ${ }^{1,2}$ Liehui Zhang, ${ }^{1}$ Beata Joanna Darowska, ${ }^{2}$ and Peng Xu' ${ }^{1}$ \\ ${ }^{1}$ State Key Laboratory of Reservoir Geology and Development Engineering, Southwest Petroleum University, Chengdu, \\ Sichuan 610500, China \\ ${ }^{2}$ Chengdu North Petroleum Exploration and Development Technology Company Ltd., Chengdu, Sichuan 610051, China
}

Correspondence should be addressed to Bo Kang; 49872897@qq.com and Liehui Zhang; zhangliehui@vip.163.com

Received 9 September 2016; Revised 13 November 2016; Accepted 24 November 2016

Academic Editor: Khosrow Naderi

Copyright ( 2016 Jian Wang et al. This is an open access article distributed under the Creative Commons Attribution License, which permits unrestricted use, distribution, and reproduction in any medium, provided the original work is properly cited.

\begin{abstract}
In this paper, the flowing mechanism and function on the macroscopic and microscopic scale in the porous media of a widely used weak gel of an acrylamide based polymer crosslinked with chromium(III) were studied. Innovative microscopic plane visualization model was designed for microscopic scale experiment and sand pack physical model for macroscopic scale. The microscopic displacing experiments indicate that weak gel mainly intrudes into big pores rather than small ones, which can improve the conformance horizontally and increase the sweep efficiency benefiting from fluid diversion. Additionally, due to good viscoelasticity of weak gel, the negative pressure effect was formed enhancing oil recovery flow from small pore throats. Results of macroscopic physical sand pack flow experiment indicate positive influence of weak gel on vertical conformance control. Although the high permeable layer was not completely blocked, the oil recovery improved as a result of weak gel movement by continuous water flooding. Experiments results lead to conclusion, the primary function of weak gel is oil displacement, profile modification is secondary, and its effect is temporary.
\end{abstract}

\section{Introduction}

Major problems [1-3] during the water flooding operations are early water breakthrough and high water cut in the produced fluids. They are attributed to the reservoir heterogeneity, presence of high permeability streaks, and permeability variations $[4,5]$. Injected water mainly invades into higher permeable sections of the reservoir leaving significant amounts of oil in low permeability channels, decreasing water sweep efficiency and causing low oil recovery. It generates additional costs and reduces single well's economical life span. Polymer gel systems have emerged over the last decade as one of the most effective tools for controlling water production [6-10]. Injected gel flows into high permeability channels, reducing the permeability and diverting water into low permeability sections, increasing swept volume and oil recovery. Weak gel system (WG) was designed for in-depth profile modification [11-13] and is characterized by low polymer and crosslinker concentration, low surface viscosity, delayed gelling time, and good viscoelasticity. It is prepared using complex polymer, an organic crosslinker, and additional agent. Gel system is formed by intramolecular and intermolecular crosslink [14].

Due to relatively low cost and high success rate, hydrolyzed polyacrylamide (HPAM) is commonly used. Chromium(III) acetate $(\mathrm{Cr}(\mathrm{III}))$ is widely used as a crosslinker. Burrafato et al. [15] conducted experiments to study the evidence of molecular $\mathrm{Cr}$ (III) crosslinks in $\mathrm{Cr}(\mathrm{III}) / \mathrm{HPAM}$ gels, showing that gelation occurs between $\mathrm{PH} 2.3$ and 6.7 and the time of gelation increases dramatically at low $\mathrm{PH}$. Lockhart studied the chemical properties of $\mathrm{Cr}(\mathrm{III}) / \mathrm{HPAM}$ gels; $\mathrm{Cr}$ (III) forms molecular crosslinking complexes with HPAM and displays chemical reactivity typical of inorganic coordination complexes. Lockhart [16] concluded that kinetics of network formation depend strongly on retardant concentration and temperature by studying the viscoelastic behavior of $\mathrm{Cr}(\mathrm{III}) / \mathrm{HPAM}$. Nijenhuis et al. [17] stated that the alkaline environment could promote the gelation rate 

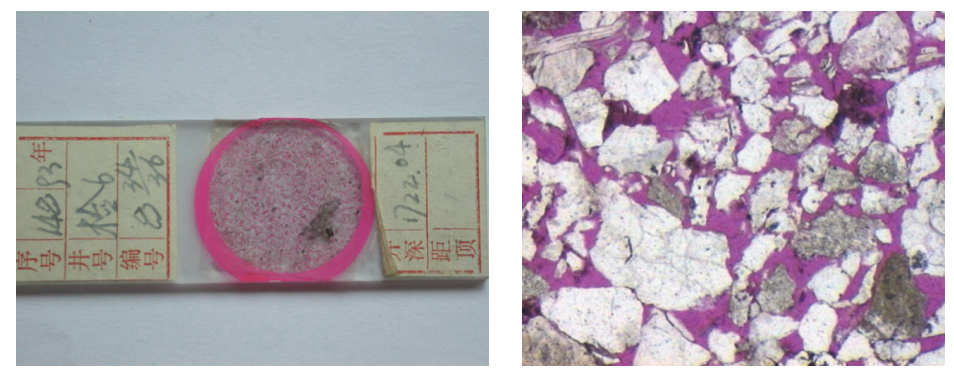

High permeability casting slice
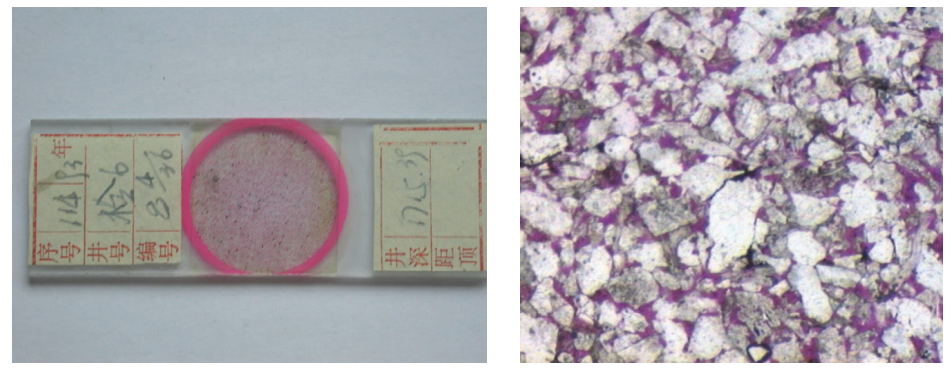

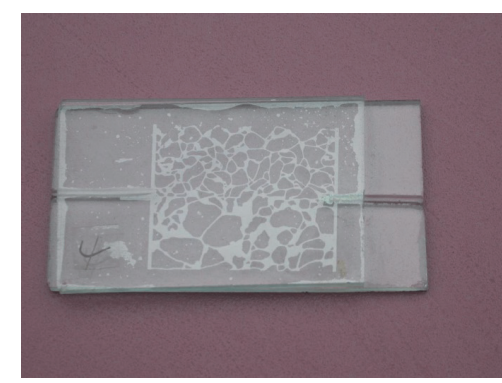

High and low permeability combination model

Low permeability casting slice

FIGURE 1: Microscopic plane visualization model.

and strength. The gelation rate can be increased properly by increasing the $\mathrm{pH}$ value. Nijenhuis [18] calculated the equilibrium constants of various candidates for the crosslinking reaction, showing that the crosslinks consist of two carboxylic acid anions coordinated with the dimerisation product of the Cr(III). Gallino et al. [19] used the gel point, GP, to describe the gelation kinetics of $\mathrm{Cr}$ (III)/HPAM solutions, experiment results prove that the amount of $\mathrm{Cr}$ (III) reacting at the GP is constant for a given polymer and solution $\mathrm{pH}$ has been obtained, and the gelation reaction is of first order in $\mathrm{Cr}$ (III) rather than second order. Klaveness et al. [20] introduced the dynamic storage modulus, $G^{\prime}$, to study the gelation process mechanism, indicating that the observed biphasic natures of the first-order plots from rheology and spectroscopy measurements are due to a side reaction; the cross-linking can proceed through a rate-determining introduction of the first HPAM to Cr(III). Krul et al. [21] used 13 C NMR to study the interaction of $\mathrm{Cr}$ (III)/HPAM gel, which showed that formation of the complex is a driving force of the interaction, the complex contains two or three carboxylate groups, and the amide units are not involved in any specific interaction with the cation. Jin et al. [22] investigated the relationship between gelation performance and microstructures of $\mathrm{Cr}$ (III)/HPAM gel. Ganguly [23] concluded that $\mathrm{Cr}$ (III)/HPAM gel can be used for conformance control in fractured reservoir and an experiments and conceptual model developed to study the displacement of gelling mixture. Lu et al. [24] studied the performance characteristics of $\mathrm{Cr}$ (III)/HPAM gel and its application in Bohai Oilfield; the results showed that this gel system exhibits a great effect on enhancing oil recovery and decreasing water cut from pilot tests data.

However, the available research focuses on the study of gelation mechanism and working performance of the Cr(III)/HPAM gel. The microscopic displacement mechanism of $\mathrm{Cr}$ (III)/ HPAM weak gel flowing through porous media is still not well understood. The failure or success of Cr(III)/HPAM gel treatment project is highly related to the better understanding of the flowing behavior of $\mathrm{Cr}$ (III)/HPAM gel in porous media. In addition, multiple researches concentrate on conformance control performance of $\mathrm{Cr}$ (III)/HPAM weak gel from laboratory investigation, but only few reported whether weak gel has positive influence on residual oil displacement.

In this paper, we conduct microexperiment to study the microscopic displacement mechanism of Cr(III)/HPAM gel and core flooding experiment to investigate the conformance control performance from macroscopic aspect. To achieve this goal, a microscopic visualization model and a sand pack flowing model were created.

\section{Experiment}

\subsection{Setup}

2.1.1. Microscopic Visualization Model. The setup was designed to study the microscopic displacement mechanism. Figure 1 illustrates the equipment used for the oil displacement experiments. A parallel installed model is divided into higher permeability layer on the top and lower permeability layer at the bottom, each of size $10 \mathrm{~cm} \times 10 \mathrm{~cm}$, to separately simulate different flowing pace. Setup design allowed observing injected fluid flow in the high and low permeable area simultaneously. The physical properties of the model are shown in Table 1. Experiment setup included one Teledyne ISCO model 500D syringe pump (used for brine and weak gel injection), one HSC-250 $\times 2$ microscopic camera, and one computer to monitor, record, and analyze the experiment results (Figure 2). 
TABLE 1: Physical properties of the microscopic model.

\begin{tabular}{lcccc}
\hline Number & Permeability type & Porosity $(\%)$ & Permeability $(\mathrm{md})$ & ${\text { Specific surface }\left(\mu \mathrm{m}^{-1}\right)}^{2}$ \\
\hline 1 & high & 21.2 & 2517.8 & 0.3 \\
2 & low & 15.5 & 213.9 & 0.3 \\
\hline
\end{tabular}

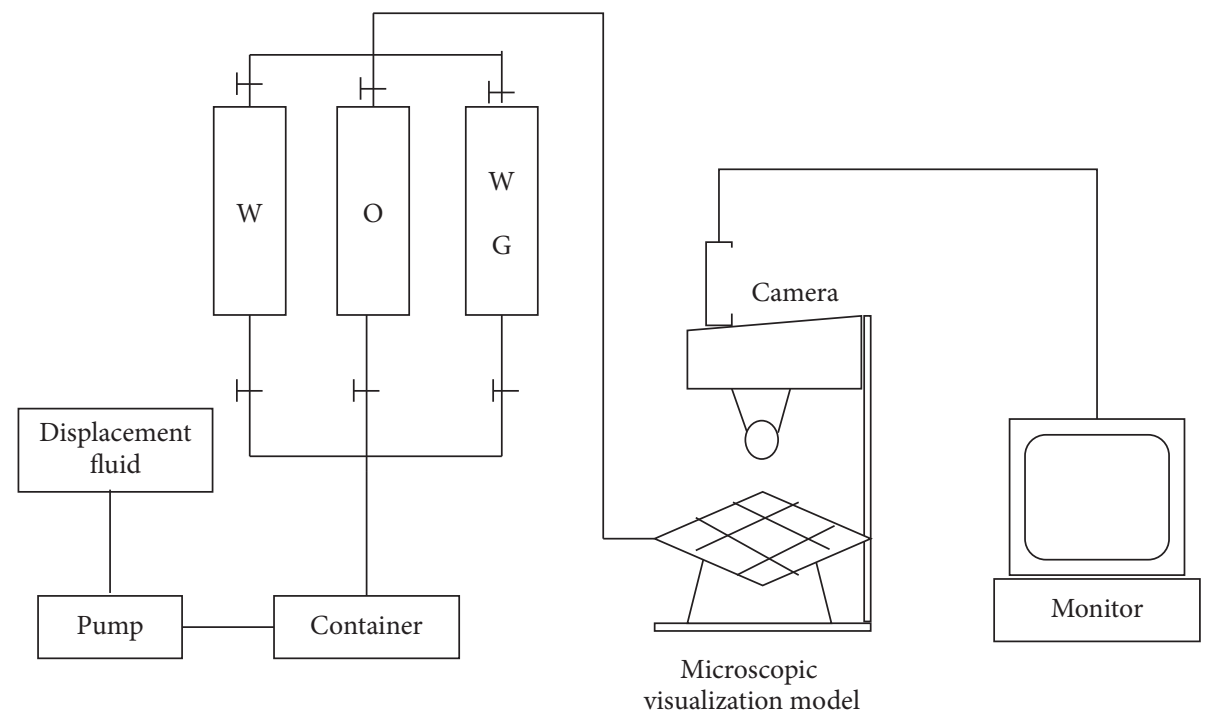

FIgURE 2: Schematic of microscopic visualization model.

2.1.2. Macroscopic Physical Sand Pack Flowing Model. The effect of weak gel on macroscopic profile modification was studied by parallel core flood experiments. Experiment setup shown in Figure 3 included one Teledyne ISCO model 500D syringe pump (used for brine and weak gel injection), two sand pack columns with length of $50 \mathrm{~cm}$ and $2.5 \mathrm{~cm}$ diameter, and three containers with oil, water, and weak gel, respectively. Sand packs and containers were connected by pressure gauge to record the pressures. Two cylinders were used to measure the oil and water output for higher and lower permeability sandstones.

2.2. Materials Used in Experiment. Weak gel system, partially hydrolyzed polyacrylamide polymer, and chromium acetate crosslinkers were prepared with following properties:

(i) The preferable molecular weight of $1500 \times 10^{4}$

(ii) Degree of hydrolysis $10-15 \%$

(iii) Polymer concentration of $2270 \mathrm{mg} / \mathrm{L}$

(iv) Cross agent concentration of $1700 \mathrm{mg} / \mathrm{L}$

(v) Weak gel viscosity of $5000 \mathrm{mPa} \cdot \mathrm{s}$

Oil samples were acquired from Liaohe oilfield. Samples' properties were as follows:

(i) Viscosity of $185.4 \mathrm{mPa} \cdot \mathrm{s}$ under $70^{\circ} \mathrm{C}$

(ii) Oil was diluted with kerosene to simulate low viscosity oil

All experiments were conducted under the temperature of $70^{\circ} \mathrm{C}$.

\section{Experiment Procedure}

3.1. Microscopic Displacement. In order to observe flow differences among weak gel, oil, and water, the injected water was colored with Methyl blue (an aromatic heterocyclic compound, widely used as biological dye). Model described in Figure 1 was installed with microscopic model (properties are shown in Figure 2); subsequent steps were as follows: (I) connecting pumps; (II) setting displacement parameters; (III) turning on the camera; (IV) injecting water and then oil to simulate reservoir conditions; (V) water flooding oil; (VI) injecting weak gel; (VII) flooding with water. Each step of the experiment was recorded for analysis. Weak gel behavior and oil displacement were studied. In all figures used in this paper, blue represents water, black represents oil, and thick yellow lines represent gel, which is transparent and its movement can only be observed in the video recorded during the experiment.

3.2. Macroscopic Flooding. Preparing experiment setup was described in Figure 3: (I) preparing sand pack (properties are shown in Table 2); (II) injecting the brine with constant flow rate of $30 \mathrm{~mL} / \mathrm{h}$; (III) measuring each sand pack's tube output; (IV) calculating water absorption ratio and the oil displacement efficiency in the sand pack's tube; (V) injecting prepared solutions with HPAM concentration $0.2 \%$ and $\mathrm{Cr}$ (III) crosslinking agent $0.2 \%$ for $0.3 \mathrm{PV}$ at the same rate; (VI) $72 \mathrm{~h}$ shut in for gel forming (conditions identical with reservoir); (VII) injecting brine with the flow rate of $30 \mathrm{~mL} / \mathrm{h}$; (VIII) measuring the output of each sand pack's 
TABLE 2: Sand pack parameters.

\begin{tabular}{cccccc}
\hline Number & Permeability type & Porosity $(\%)$ & Permeability $\left(\times 10^{-3} \mu \mathrm{m}^{2}\right)$ & Oil saturation $(\%)$ & Recovery $(\%)$ \\
\hline \multirow{2}{*}{ High } & 30.4 & 2654.6 & 65.1 & 73.0 \\
& Low & 26.3 & 263.8 & 71.7 & 32.1 \\
\hline
\end{tabular}

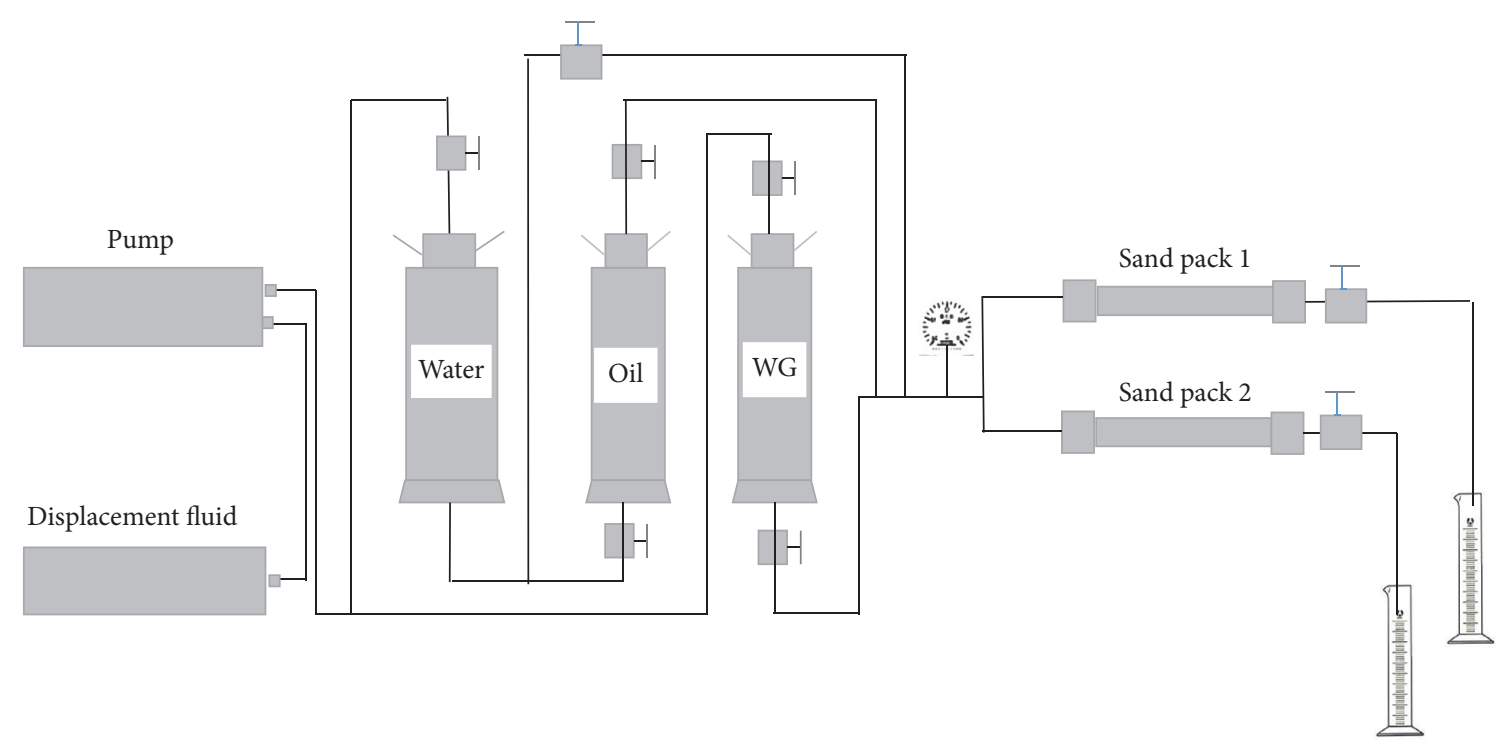

FIGURE 3: Schematic of macroscopic physical sand pack flowing Model.

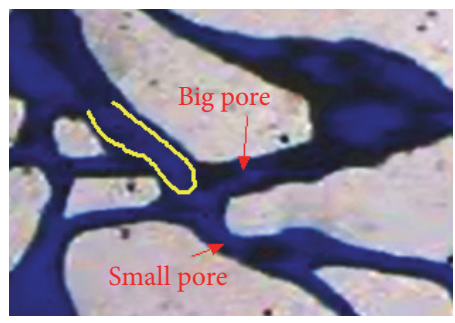

(a)

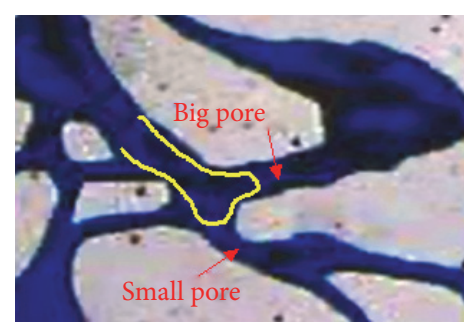

(b)

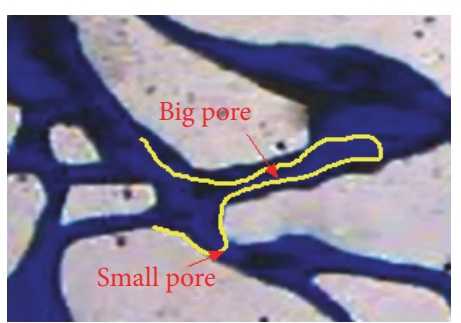

(c)

FIGURE 4: Weak gel flow pattern.

tube; (IX) calculating the water adsorption ratio and the oil displacement efficiency.

\section{Results Analysis}

4.1. Microscopic Displacement Experiment Results. Injected water mainly flooded the high permeable zone with larger pores; only insignificant amount of water entered into lower permeability area causing much slower oil flow. This indicates that injected water flows mainly through preferential flowing channels resulting in water breakthrough, negatively affecting oilfield development and production. Injected gel had to overcome flowing resistance before entering the pores. Encountering smaller resistance, gel naturally flew into bigger pores under constant injection pressure as shown in Figure 4, following higher permeability and porosity channels previously penetrated by water. Previous study [25, 26] indicates that, in large channels formed by long term erosion, rock surface is smoother and resistance is smaller; thus shearing degree of the weak gel is relatively low and flow is much smoother.

Weak gel plugged big pores diverting the injected water flow into small pore spaces under increasing pressure gradient. Improvement of oil displacement in small pores is evident. Fluids flow is shown in Figure 5. For the needs of this paper and clear visualization, yellow lines are used to mark gel movements and green lines show water movement. Due to the weak gel transparency, this process can only be observed in the video recorded during the experiment. Fluids were injected separately in stages ((1) water, (2) gel, and (3) water) to observe the flow pattern and fluids behavior. This method ensures the differentiation between water flow and weak gel behavior, confirmed by oil displacement during injections.

Initially injected water and weak gel flew through pore 2 , obviously bigger than pore 1 (Figure 5). Big distance between pores 2 and 3 caused temporary entrapment of 


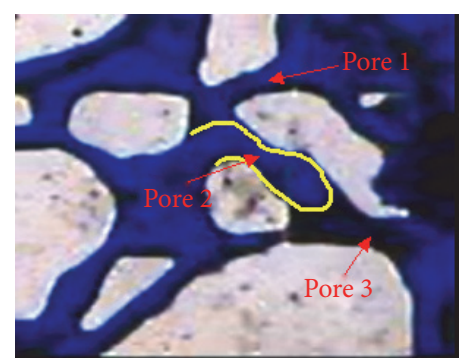

(a)

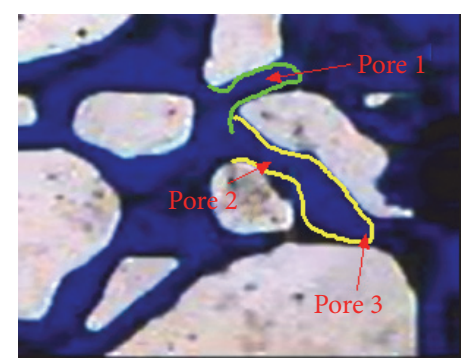

(b)

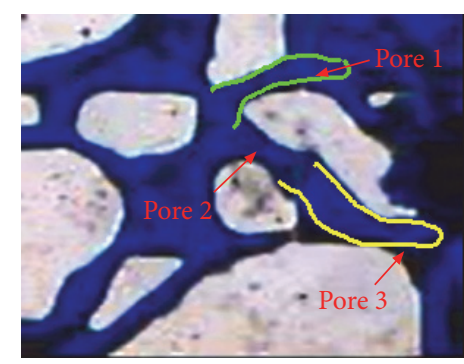

(c)

FIGURE 5: Water flowing diversion by weak gel.

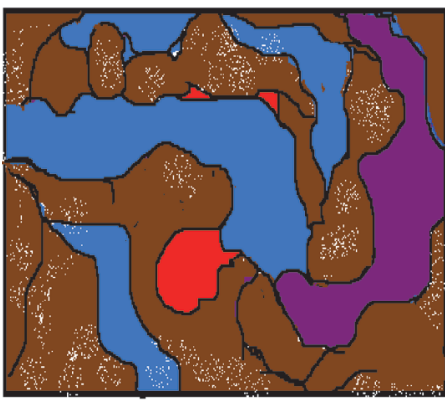

(a)

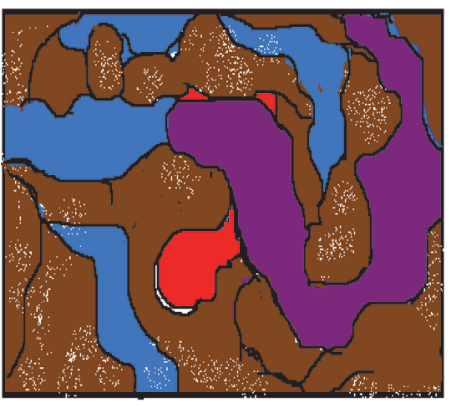

(b)

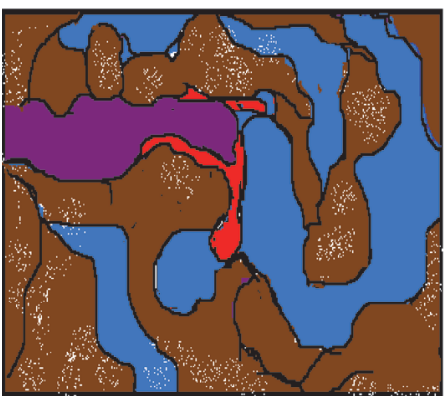

(c)

FIgURE 6: Negative pressure and viscoelasticity effect. Purple, weak gel; blue, water; red, oil.

weak gel, due to Wiesenberger effect. As a result, water injected afterwards flew through pore 1 displacing the oil. After increasing water injection volume, weak gel was pushed through pore 3. Experiment conducted in the laboratory indicates weak gel's ability to divert fluid flow path and conformance improvement.

Crosslinked molecular structure of weak gel is relatively stable and shows good viscoelasticity. After flooding with water, there is a clear boundary between two fluids; they do not react with each other. Once the gel reaches bigger pores with relatively smaller flow resistance, the process is quick and smooth. The pressure in injection channel is higher than in surrounding environment. Subsequently injected water cannot instantly fill empty space left by weak gel and creates "negative pressure." Effect of inertia and "negative pressure" help oil in small pores and throats to overcome inner threshold pressure and pulls it into the oil flow [10], improving the sweep efficiency. This phenomenon was observed during the experiment and its mechanism is illustrated in Figure 6.

4.2. Macroscopic Physical Sand Pack Flowing Results. Water, weak gel solutions, and subsequent water were injected separately in 3 phases, into the same inlet of two parallel sand packs with different permeability. During the water displacing oil phase, the injection pressure difference caused increase of oil recovery factor (Figure 7). As a result of the permeability difference between the parallel sand packs, the injected water mainly intruded into high permeability sand pack (HPS) rather than low permeability sand pack (LPS).

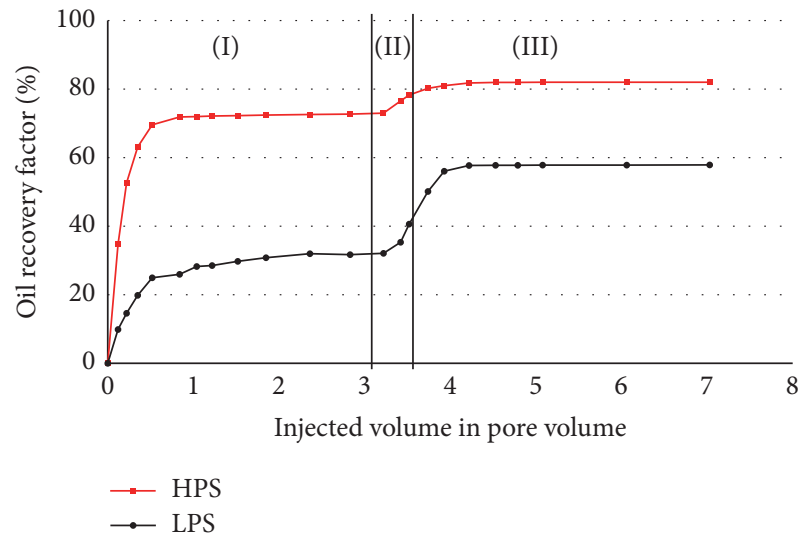

FIGURE 7: Oil recovery factor curves ((I) water injection, (II) weak gel injection, and (III) water injection).

The water breakthrough in HPS caused rapid increase of water cut (Figure 8). During the water injection, pressure difference increased and stabilized after the water breakthrough (Figure 9). The oil recovery reached up to $73.0 \%$ in HPS and $32.1 \%$ in LPS. Significant amount of oil was left in LPS.

Polymer and crosslinker before forming the gel have low viscosity; thus good injectivity of solution was ensured during the injection. The injected solution penetrated the HPS with low resistivity. Due to high viscosity of the gelant system, the flowing resistance increased, squeezing the injected solution into smaller pores, flooding oil. After $0.3 \mathrm{PV}$ gel solution was 
TABLE 3: Results of weak gel profile modification and oil displacement $\left(70^{\circ} \mathrm{C}\right)$.

\begin{tabular}{|c|c|c|c|c|c|c|c|c|c|c|}
\hline \multirow{2}{*}{ Number } & \multirow{2}{*}{$\begin{array}{l}\text { Permeability } \\
\text { type }\end{array}$} & \multirow{2}{*}{$\begin{array}{l}\text { Permeability } \\
\text { difference }\end{array}$} & \multirow{2}{*}{$\begin{array}{l}\text { WG injection } \\
\text { volume }(\mathrm{PV})\end{array}$} & \multirow{2}{*}{$\begin{array}{l}\text { Viscosity } \\
(\mathrm{mPa} \cdot \mathrm{s})\end{array}$} & \multicolumn{2}{|c|}{$\begin{array}{l}\text { Water absorption } \\
\text { ratio }\end{array}$} & \multirow{2}{*}{$\begin{array}{l}\text { Injection } \\
\text { pressure } \\
(\mathrm{Mpa})\end{array}$} & \multirow{2}{*}{$\begin{array}{c}\text { Profile } \\
\text { improvement } \\
(\%)\end{array}$} & \multirow{2}{*}{$\begin{array}{l}\text { IOR } \\
(\%)\end{array}$} & \multirow{2}{*}{$\begin{array}{c}\text { Oil } \\
\text { recovery } \\
\text { factor }(\%)\end{array}$} \\
\hline & & & & & $\begin{array}{l}\text { Before gel } \\
\text { treatment }\end{array}$ & $\begin{array}{l}\text { After gel } \\
\text { treatment }\end{array}$ & & & & \\
\hline \multirow{2}{*}{1} & High & \multirow{2}{*}{10.1} & 0.2 & \multirow{2}{*}{5123.5} & \multirow{2}{*}{$65.1 / 14.3$} & \multirow{2}{*}{$3.2 / 23.5$} & 0.2 & \multirow{2}{*}{$97.4 \%$} & 9.0 & 82.0 \\
\hline & Low & & 0.1 & & & & 0.4 & & 25.5 & 57.6 \\
\hline
\end{tabular}

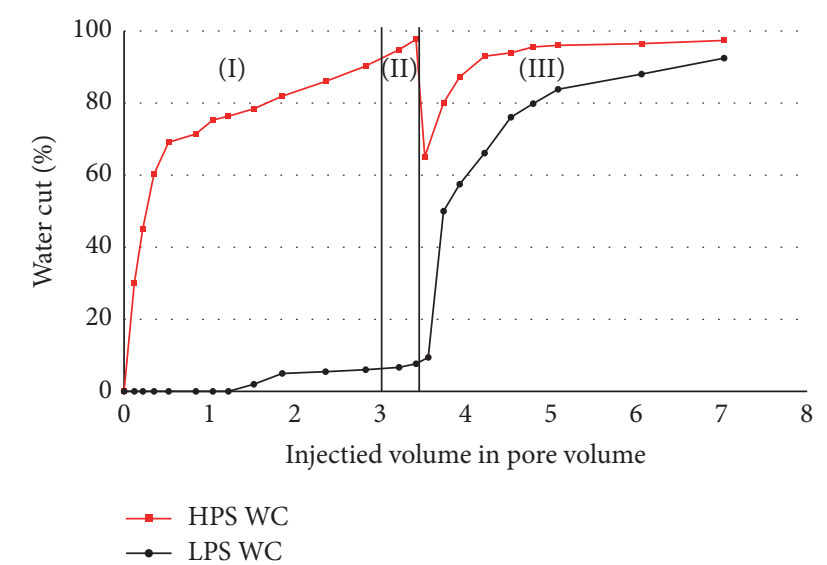

FIgURE 8: Water cut curves ((I) water injection, (II) weak gel injection, and (III) water injection).

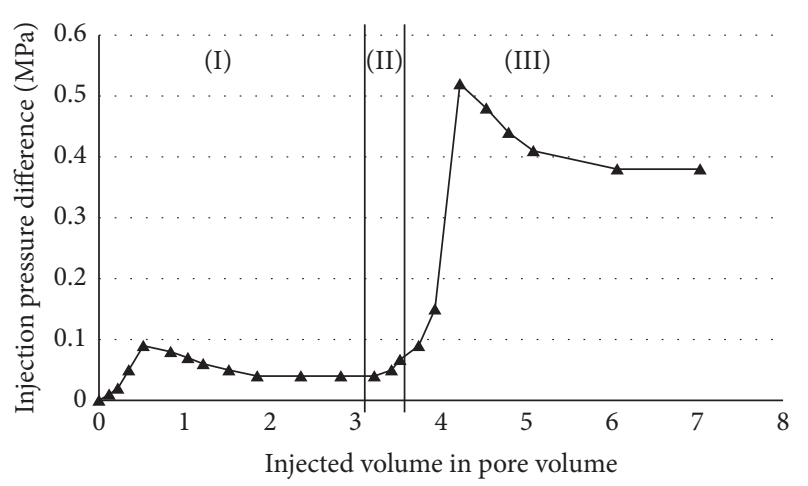

FIGURE 9: Injection pressure difference curves ((I) water injection, (II) weak gel injection, and (III) water injection).

injected, $72 \mathrm{~h}$ shut in for gel forming (conditions identical with reservoir).

In the subsequent water injection phase, the gel exhibited good blockage performance in the HPS, causing the decrease of water cut and the injection pressure increase (Figures 8 and 9). The injected water was diverted into LPS, flooding the oil. The improved recovery reached up to $25.5 \%$ simultaneously increasing water cut in the LPS. Unlike the bulk gel or particle gel, the weak gel, due to its flowing capacity and water solubility, did not block the high permeability sand pack completely; with the increase of pressure difference, the injected water flooded the weak gel system pushing it slowly, sweeping the oil in HPS. The oil recovery increased by $9.0 \%$. These results are consistent with the microscopic displacement results. Weak gel penetrates large pores selectively forming temporary barrier, helping water flood low permeability zones and improving oil recovery.

Experiments results prove weak gel's ability to modify the profile and displace oil. Based on the experiment results, profile improvement ratio exceeded 95\% (Table 3). The migration of weak gel in the porous media can be influenced by stretching and shearing of rock matrix and diluting by water. Initially, after injection, weak gel invaded large pore channels. Flooding pressure increased and permeability was reduced. With the increased amount of injected water, the gelant strength decreased. Weak gel was pushed forward, in some cases even out of the high permeability zones.

Based on those results and analysis, it can be concluded that the major function of weak gel is oil displacement, and the secondary function is conformance control but the effect is temporary.

\section{Conclusions}

(1) Microscopic displacement experiment results show that the improving profile and oil displacement mechanism of weak gel is as follows: (I) Weak gel intrudes large pores selectively increasing the conformance and diverting the fluid flow. (II) Weak gel migration forms negative pressure oil absorption improving the sweep efficiency.

(2) The parallel sand pack flowing experiment results indicate that weak gel flows into high permeable water flooded zones plugging it and diverting subsequent water into the relatively low permeability area driving out the remaining oil. Due to water solubility and viscoelasticity, weak gel exhibits a certain degree of mobility and cannot completely block the reservoir.

(3) The migration and deformation of weak gel in the porous media imply that the primary role of weak gel is displacement and the conformance control is only temporary.

\section{Competing Interests}

All the authors declare that there is no conflict of interests regarding the publication of this paper.

\section{Acknowledgments}

This work was supported by a grant from the National Natural Science Foundation of China (Grant no. 51574200) and the Natural Science Foundation of China (Grant no. 51374181). 


\section{References}

[1] H. G. Wang and W. K. Guo, "Study and application of weak gel system prepared by complex polymer used for depth profile modification," Society of Petroleum Engineers Journal, vol. 28, pp. 387-401, 2013.

[2] S. L. Bryant, M. Bartosek, T. P. Lockhart, and D. Giacca, "Polymer gelants for high temperature water shutoff applications," SPE Journal, vol. 2, no. 4, pp. 447-454, 1997.

[3] Y. Zhang, "Study on effect of profile controlling and flooding system of weak gel on gelling properties," Natural Gas and Oil, vol. 31, no. 4, pp. 70-72, 2013.

[4] Y. Liu, B. Bai, and Y. Wang, "Applied technologies and prospects of conformance control treatments in China," Oil and Gas Science and Technology, vol. 65, no. 6, pp. 859-878, 2010.

[5] R. Jain, C. S. McCool, D. W. Green, G. P. Willhite, and M. J. Michnick, "Reaction kinetics of the uptake of chromium(III) acetate by polyacrylamide," SPE Journal, vol. 10, no. 3, pp. 247254, 2005.

[6] C. A. Grattoni, H. H. Al-Sharji, C. Yang, A. H. Muggeridge, and R. W. Zimmerman, "Rheology and permeability of crosslinked polyacrylamide gel," Journal of Colloid and Interface Science, vol. 240, no. 2, pp. 601-607, 2001.

[7] J. Wang, Y. Huang, H. J. Gu et al., "Optimization study of injection parameters for weak gel displacement control in conglomerate oil reservoir," Petroleum Geology and Recovery Efficiency, vol. 13, no. 1, pp. 90-91, 2006.

[8] J. C. Mack and J. E. Smith, "In-depth colloidal dispersion gels improve oil recovery efficiency," in Proceedings of the 9th Symposium on Improved Oil Recovery, pp. 527-539, Society of Petroleum Engineers, Tulsa, Okla, USA, April 1994.

[9] A. Stavland and H. C. Jonsbraten, "New insight into aluminum citrate/polyacrylamide gels for fluid control," in Proceedings of the 10th Symposium on Improved Oil Recovery of Society of Petroleum Engineers, pp. 347-356, Tulsa, Okla, USA, April 1996.

[10] X.-J. Zhao and C.-J. Wang, "A study on microscopic profiling/oil displacing mechanisms in weak gel flooding," Oilfield Chemistry, vol. 21, no. 1, pp. 56-60, 2004.

[11] J. Vasquez, E. D. Dalrymple, L. Eoff, B. R. Reddy, and F. Civan, "Development and evaluation of high-temperature conformance polymer systems," in Proceedings of the SPE International Symposium on oilfield Chemistry, Woodlands, Tex, USA, February 2005.

[12] W. Sun, Z. H. Qu, and G. Q. Tang, "Characterization of water injection in low permeable rock using sandstone micro-model," in Proceedings of the SPE International Thermal Operations and Heavy Oil Symposium and Western Regional Meeting, Society of Petroleum Engineers, Bakersfield, Calif, USA, March 2004.

[13] U. S. Yadav and V. Mahto, "Rheological Study of partially hydrolyzed polyacrylamide-hexamine-pyrocatchol gel system," International Journal of Industrial Chemistry, vol. 4, no. 1, p. 8, 2013.

[14] X. Y. Gu, H. B. Sang, C. S. Pu et al., Effect of pH on Gelling Performance and Stability of HPAM/Cr(III) Weak Gel, International Forum on Energy, Environment Science and Materials, 2015.

[15] G. Burrafato, S. Carminati, F. Bonaccorsi, and T. P. Lockhart, "Evidence for molecular Cr3+ cross-links in Cr3+/polyacrylamide gels," Macromolecules, vol. 23, no. 8, pp. 2402-2406, 1990.

[16] T. P. Lockhart, "Chemical properties of chromium/polyacrylamide gels," SPE Advanced Technology Series, vol. 2, no. 2, pp. 199-205, 1994.
[17] K. T. Nijenhuis, A. Mensert, and P. L. J. Zitha, "Viscoelastic behaviour of partly hydrolysed polyacrylamide/chromium(III) gels," Rheologica Acta, vol. 42, no. 1, pp. 132-141, 2003.

[18] K. T. Nijenhuis, "Crosslink nature in $\mathrm{Cr}(\mathrm{III})$-polyacrylamide gels," Macromolecular Symposia, vol. 171, no. 1, pp. 189-200, 2001.

[19] G. Gallino, M. Molinari, and T. P. Lockhart, "Rheological studies of the gelation kinetics of $\mathrm{Cr}^{+3}$-polyacrylamide solutions," Makromolekulare Chemie. Macromolecular Symposia, vol. 45, no. 1, pp. 137-144, 1991.

[20] T. M. Klaveness, P. Ruoff, and J. Kolnes, "Kinetics of the crosslinking of poly(acrylamide) with $\mathrm{Cr}$ (III). 3. Rheological measurements of the gelation," The Journal of Physical Chemistry, vol. 99, no. 20, pp. 8255-8259, 1995.

[21] L. P. Krul, A. V. Shakhno, E. V. Grinyuk et al., "Interaction of carboxylated polyacrylamide with chromium(III) acetate: ${ }^{13}$ C NMR study of mechanism," Russian Journal of General Chemistry, vol. 83, no. 11, pp. 2027-2031, 2013.

[22] F.-Y. Jin, C.-D. Yuan, W.-F. Pu et al., "Investigation on gelation process and microstructure for partially hydrolyzed polyacrylic amide (HPAm)-Cr(III) acetate-methanal compound crosslinked weak gel," Journal of Sol-Gel Science and Technology, vol. 73, no. 1, pp. 181-191, 2015.

[23] S. Ganguly, "Displacement of Cr(III)-partially hydrolyzed polyacrylamide gelling solution in a fracture in porous media," Transport in Porous Media, vol. 84, no. 1, pp. 201-218, 2010.

[24] X. Lu, W. Wang, R. Wang et al., "The performance characteristics of Cr3+ polymer gel and its application analysis in bohai oilfield," in Proceedings of the International Oil and Gas Conference and Exhibition in China, SPE-130382-MS, Beijing, China, June 2010.

[25] M. Bartosek, A. Mennella, and T. Lockhart, "Polymer gels for conformance treatments: propagation of $\mathrm{Cr}$ (III) crosslinking in porous media," Journal of Petroleum Science and Engineering, vol. 16, pp. 1-13, 1996.

[26] L. H. Zhang, J. Tong, Y. Xiong, and Y. L. Zhao, "Effect of temperature on the oil-water relative permeability for sandstone reservoirs," International Journal of Heat and Mass Transfer, vol. 105, pp. 535-548, 2017. 

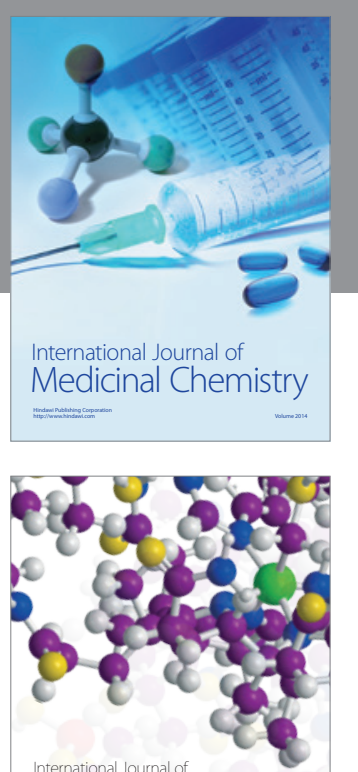

Carbohydrate Chemistry

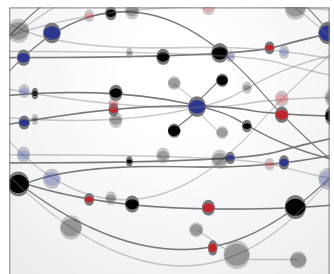

The Scientific World Journal
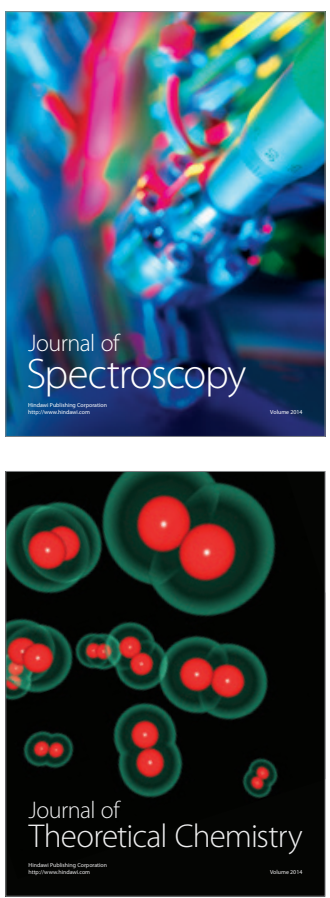
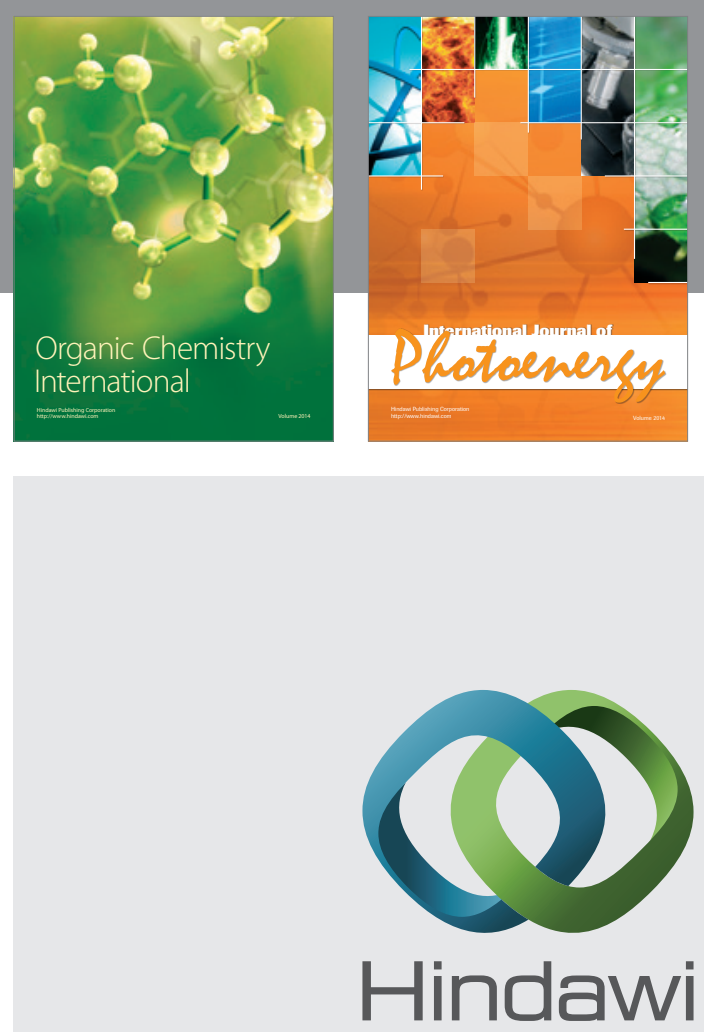

Submit your manuscripts at

http://www.hindawi.com

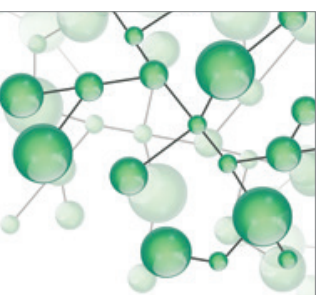

International Journal of

Inorganic Chemistry

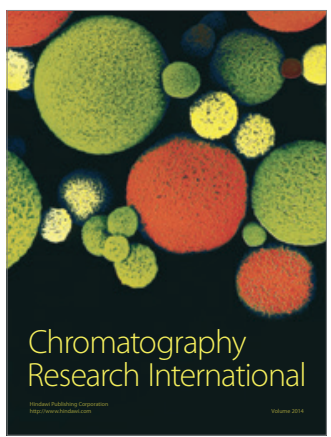

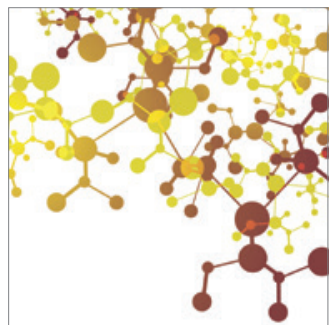

Applied Chemistry
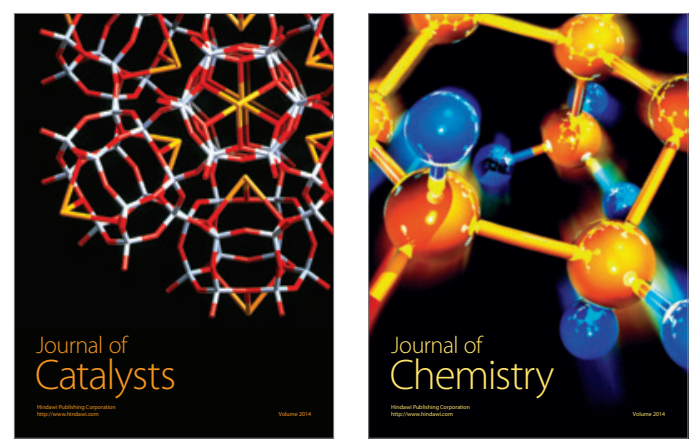
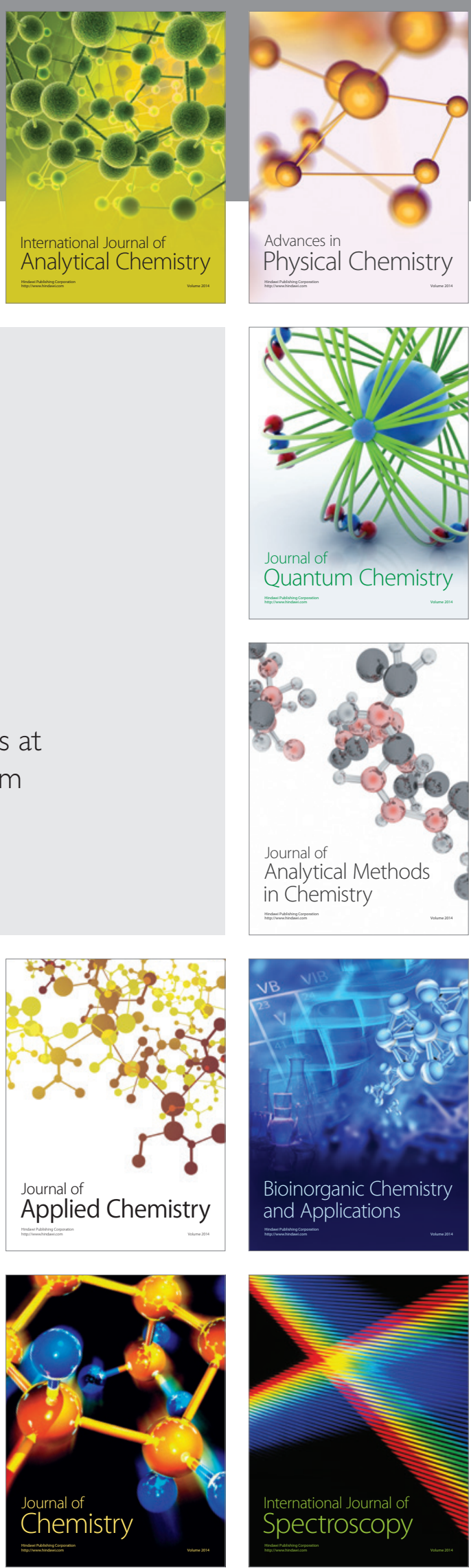